\title{
Ion Induced Promotion of Activity Enhancement of Mesoporous Manganese Oxides for Aerobic Oxidation Reactions
}

Sourav Biswas, Altug S. Poyraz, Yongtao Meng, Chung-Hao Kuo, Curtis Guild, Hannah Tripp and Steven L. Suib*

Correspondence: Professor Steven L. Suib, Department of Chemistry and Institute of Materials

Science, University of Connecticut, 55 North Eagleville Road, U-3060, Storrs, Connecticut 06269,

United States.Phone; (860) 486-2797,Fax; (860) 486-2981, Email; steven.suib@uconn.edu

Abstract : Inverse micelle templated mesoporous manganese oxide (University of Connecticut mesoporous material, UCT-1) and ion promoted mesoporous manganese oxides (UCT-18-X, X = $\mathrm{Mg}^{2+}, \mathrm{Ca}^{2+}, \mathrm{K}^{+}, \mathrm{Na}^{+}$and $\mathrm{Cs}^{+}$) having trace amount of alkali metal ions as promoters with tunable porosity and crystallinity were synthesized. The synthesis was based on the use of inverse micelles as soft templates and unique NOx chemistry as established for recently discovered UCT materials. The materials were tested for selective aerobic alcohol oxidation and the catalytic activity followed the order of UCT-1 <UCT-18-Mg <UCT-18-Ca <UCT-18-K <UCT-18-Na <UCT-18-Cs. The catalytic activity was correlated to the promoter ion induced increase in basicity of the materials. The retention of an amorphous structure, low reducibility, and the effects of lattice oxygen are other key factors responsible for the enhanced catalytic activity. The UCT-18-Cs catalyst was found to oxidize various alcohols to corresponding aldehydes and ketones selectively (100\% selectivity) with very high conversion (as high as $100 \%$ ). The UCT-18-Cs also exhibited solvent free green oxidation of 1.3.5-trimethylbenzene to yield 3,5-dimethylbenzoic acid and (3,5dimethylphenyl)methyl ester with $>90 \%$ conversion and $90 \%$ selectivity for the acid and $9 \%$ selectivity for the ester. 


\section{Introduction}

Since the discovery of mesoporous silica and aluminosilicates (M41S family) by Mobil Oil Corporation in 1992 [1] mesoporous materials have attracted a great deal of interest in the field of heterogeneous catalysis in organic transformations [2, 3]. Specifically, mesoporous transition metal oxides (MTMO) have shown promise for performing a wide range of catalytic organic transformations due to the coexistence of multiple oxidation states [4]. Transition metal oxides can be further modified with several dopants and promoter ions to design a specific catalyst for specific reactions [5-8]. Among the transition metal oxides, manganese oxides deserve a special interest, since manganese can exist in more than five stable and easily exchangeable oxidation states with multiple structural forms over a wide range of temperatures. Manganese oxides have a wide range of catalytic applications due to highly efficient redox properties [9-11], and can be more effective in the presence of other elements [12]. Manganese oxides are also known to be effective oxidation catalysts in both the amorphous and crystalline states [13-17]. Like other transition metal oxides, manganese oxides can also accommodate cations either on the surface as promoter ions [18] or in their structures as charge balancing ions [19] (as in octahedral molecular sieve, $\mathrm{KMn}_{8} \mathrm{O}_{16} \cdot n \mathrm{H}_{2} \mathrm{O}$ or K-OMS-2, where $\mathrm{K}^{+}$resides in the tunnel for charge balancing).

Liquid phase oxidation reactions are of interest in organic chemistry as well as in industrial applications. The selective oxidation of alcohols to carbonyl compounds is one of the common and elegant classes of molecular transformations in synthetic organic chemistry. The desired carbonyl products are high value components used in fine chemicals, pharmaceutical, and perfume industries [20]. Numerous catalytic systems have been used to perform this partial oxidation of alcohols [21-23]. The two major problems associated with heterogeneous catalysts are the lifetime of the catalyst (catalyst deactivation) and the leaching of active species from the solid surface to the solution [24]. The design of an efficient heterogeneous catalyst system should ideally involve mild and environmentally friendly reaction conditions (air as the oxidant, low temperature, low catalyst loading, avoidance of toxic materials, and 
minimum waste disposal with proper reusability) in addition to high efficiency. The selective C-H bond oxidation at the benzylic position to the corresponding oxy functional products is an important and challenging aspect in synthetic organic chemistry [25-28]. For example, the methyl benzoic acids (oxidation products of methyl aromatics) have versatile use in chemical and pharmaceutical industries [29]. Traditionally, stoichiometric amounts of oxidants like potassium permanganate $\left(\mathrm{KMnO}_{4}\right)$, chromium trioxide $\left(\mathrm{CrO}_{3}\right)$, sodium dichromate $\left(\mathrm{Na}_{2} \mathrm{Cr}_{2} \mathrm{O}_{7}\right)$ and nitric acid $\left(\mathrm{HNO}_{3}\right)$ [30] are required in these oxidation reactions. The production of large amounts of toxic wastes and the requirement of difficult separation steps make these processes environmentally and industrially unfavorable. Despite the industrial importance, environmentally friendly oxidation processes are rarely described in the literature. Some efficient catalytic systems involve oxidants such as metaloxo materials, tert-Butyl hydroperoxide (TBHP) or hydrogen peroxide $\left(\mathrm{H}_{2} \mathrm{O}_{2}\right)$ and base additives [31-34]. However, these systems often suffer from low conversion (of alkylbenzenes) and require the use of conditions like high pressure and temperature. An efficient and economically feasible catalyst system should perform alkylbenzene oxidation with high selectivity towards the corresponding acid under aerobic condition.

Recently synthesized UCT (University of Connecticut) mesoporous materials form quite a large family [35]. The UCT synthetic approach allows one to synthesize different mesoporous oxide materials using a single synthetic strategy, i.e transition metals, metalloids, mixed oxides and promoted oxides [36]. The synthesis relies on inverse micelle formation and unique NOx chemistry. The NOx species are formed in situ by thermal decomposition of $\mathrm{NO}_{3}{ }^{-}$. The metal oxide nanoparticles are packed closely in a random fashion to build the mesostructure. The UCT materials were found to be active in different types of catalytic reactions. For example, Cs promoted mesoporous manganese oxide (UCT-18-Cs) exhibited a bifunctional catalytic role (oxidation and then in situ esterification). The inactivated aliphatic alcohol 1Decanol was oxidized to 1-Decanoic acid and then 1-Decanoic acid combined with 1-Decanol to produce Decyl decanoate. Whereas, nonpromoted UCT-1 and other manganese oxide catalysts (K-OMS-2, 
amorphous manganese oxide, $\mathrm{Mn}_{2} \mathrm{O}_{3}$ ) could only perform oxidation of 1-Decanol to 1-Decanal. The oxidation of inactivated long chain alcohol demonstrates the redox power of the catalyst, while the esterification is due to the basic nature of the catalyst. In this work 5 different UCT-18 materials were synthesized using 5 different promoter cations $\left(\mathrm{Mg}^{2+}, \mathrm{Ca}^{2+}, \mathrm{K}^{+}, \mathrm{Na}^{+}\right.$and $\left.\mathrm{Cs}^{+}\right)$with tunable mesostructure parameters (such as pore size, pore volume, surface area). Selective aerobic oxidations of alcohols and oxidations of inert alkylbenzenes were performed using the catalysts and the catalytic activity was also compared with conventional active manganese oxide catalysts.

\section{Experimental Section}

\subsection{Catalyst Synthesis}

Synthesis of UCT-1: In a typical synthesis $0.02 \mathrm{~mol}$ of manganese nitrate tetrahydrate $\left(\mathrm{Mn}\left(\mathrm{NO}_{3}\right)_{2} \cdot 4 \mathrm{H}_{2} \mathrm{O}\right)$ and $0.134 \mathrm{~mol}$ of 1-Butanol were added into a $120 \mathrm{~mL}$ beaker. To this solution $0.0034 \mathrm{~mol}$ of Poly(ethylene glycol)-block-poly(propylene glycol)-block-poly(ethylene glycol) (Pluoronic P123, $\mathrm{PEO}_{20} \mathrm{PPO}_{70} \mathrm{PEO}_{20}$, molar mass $\left.5750 \mathrm{~g} \mathrm{~mol}^{-1}\right)$ and $0.032 \mathrm{~mol}$ of concentrated nitric acid $\left(\mathrm{HNO}_{3}\right)$ were added and stirred at room temperature until the solution became clear (light pink). The solution was then kept in an oven at $120^{\circ} \mathrm{C}$ for $3 \mathrm{~h}$ under air. The resulting black material was washed with excess ethanol, centrifuged and dried in a vacuum oven overnight. The dried black powders were subjected to a heating cycle. First they were heated at $150^{\circ} \mathrm{C}$ for $12 \mathrm{~h}$ and cooled down to room temperature under ambient conditions followed by a second heating step of $250^{\circ} \mathrm{C}$ for $3 \mathrm{~h}$.

Synthesis of UCT-18: In a typical synthesis $0.02 \mathrm{~mol}$ of manganese nitrate tetrahydrate $\left(\mathrm{Mn}\left(\mathrm{NO}_{3}\right)_{2} .4 \mathrm{H}_{2} \mathrm{O}\right)$ and $0.134 \mathrm{~mol}$ of 1-Butanol were added into a $120 \mathrm{~mL}$ beaker. To this solution 0.0034 mol of Poly(ethylene glycol)-block-poly(propylene glycol)-block-poly(ethylene glycol) (Pluoronic P123, $\mathrm{PEO}_{20} \mathrm{PPO}_{70} \mathrm{PEO}_{20}$, molar mass $\left.5750 \mathrm{~g} \mathrm{~mol}^{-1}\right)$ and $0.032 \mathrm{~mol}$ of concentrated nitric acid $\left(\mathrm{HNO}_{3}\right)$ were 
added and stirred at room temperature until the solution became clear (light pink). To this clear solution $200 \mu \mathrm{L}$ of $1.0 \mathrm{M} \mathrm{XNO}_{3}(\mathrm{X}=\mathrm{Cs}, \mathrm{K}, \mathrm{Na})$ and $\mathrm{X}\left(\mathrm{NO}_{3}\right)_{2}(\mathrm{X}=\mathrm{Ca}, \mathrm{Mg})$ was added maintaining the $\mathrm{Mn} / \mathrm{X}$ ratio 100/1, mol/mol. The resulting clear solution was then kept in an oven at $120^{\circ} \mathrm{C}$ for $3 \mathrm{~h}$ under air. The black material was washed with excess ethanol, centrifuged, and dried in a vacuum oven overnight. The dried black powders were subjected to a heating cycle. First they were heated at $150^{\circ} \mathrm{C}$ for $12 \mathrm{~h}$ and cooled down to room temperature under ambient conditions followed by a second heating step of $250^{\circ} \mathrm{C}$ for $3 \mathrm{~h}$.

* It is recommended to perform all reactions in ovens with proper ventilation due to release of toxic NOx from the gel during the reaction.

\subsection{Catalyst Characterization}

The powder X-Ray diffraction (PXRD) analyses were performed on a Rigaku Ultima IV diffractometer ( $\mathrm{Cu}$ K $\alpha$ radiation, $\lambda=1.5406 \AA$ ) with an operating voltage of $40 \mathrm{kV}$ and a current of $44 \mathrm{~mA}$. The low-angle PXRD patterns were collected over a $2 \theta$ range of $0.5-10^{\circ}$ with a continuous scan rate of $0.5^{\circ} \mathrm{min}^{-1}$, where the wide-angle PXRD patterns were collected over a $2 \theta$ range of $5-75^{\circ}$ with a continuous scan rate of $1.0^{\circ} \mathrm{min}^{-1}$. The Nitrogen adsorption desorption experiments were done with a Quantachrome Autosorb-1$1 \mathrm{C}$ automated adsorption system. The samples were degassed at $150^{\circ} \mathrm{C}$ for $6 \mathrm{~h}$ under helium prior to measurement. The surface areas were calculated using the Brunauer-Emmett-Teller (BET) method and pore sizes and pore volumes were calculated from the desorption branch of the isotherm using the Barrett-Joyner-Halenda (BJH) method. A Zeiss DSM 982 Gemini field emission scanning electron microscope (FE-SEM) with a Schottky emitter at an accelerating voltage of $2.0 \mathrm{kV}$ and a beam current of $1.0 \mathrm{~mA}$ was used for determination of surface morphology of the materials. The samples were ultrasonically dispersed in ethanol and deposited on silicon wafers prior to the analyses. High-resolution transmission electron microscopy (HR-TEM) images were recorded on a JEOL 2010 FasTEM microscope operating at $200 \mathrm{kV}$. The samples were prepared by using a focused-ion-beam (FIB) 
technique to make thin films to be observed by HR-TEM. The $\mathrm{CO}_{2}$ chemisorption experiments were performed using a Quantachrome Autosorb-1-1C automated adsorption system. All the samples were heated in helium under vacuum at $150^{\circ} \mathrm{C}$ for $6 \mathrm{~h}$ prior to the experiment. The adsorption studies of UCT18 and UCT-1 were done at room temperature. Then both adsorption and desorption isotherms were measured for UCT-18-Cs, UCT-1, K-OMS-2 and commercial $\mathrm{Mn}_{2} \mathrm{O}_{3}$ at $0^{\circ} \mathrm{C}, 25^{\circ} \mathrm{C}$ and $-78^{\circ} \mathrm{C}$. Temperature-resolved in situ powder X-ray diffraction (TR-PXRD) analysis was performed in an XTRA X-ray diffractometer ( $\mathrm{Cu} \mathrm{K} \alpha$ radiation) equipped with an Anton Parr XRK 900 heating chamber. The structural stabilities of UCT-1 and UCT-18 Cs materials were investigated from $250^{\circ} \mathrm{C}$ to $550^{\circ} \mathrm{C}$ using a ramp rate of $5^{\circ} \mathrm{C} \min ^{-1}$ under air. Diffraction patterns were obtained in the range of $5-75^{\circ} 2 \theta$ at a scanning rate of $2.0^{\circ} \mathrm{min}^{-1}$. X-ray photoelectron spectroscopy (XPS) was done on a PHI model 590 spectrometer with multiprobes (ФPhysical Electronics Industries Inc.), using Al-K radiation $(\lambda=1486.6 \mathrm{eV})$ as the radiation source. The powder samples were pressed on carbon tape mounted on adhesive copper tape stuck to a sample stage placed in the analysis chamber. The XPS spectra were analyzed and fitted using CasaXPS software (version 2.3.12). The $\mathrm{C} 1 \mathrm{~s}$ photoelectron line at $284.6 \mathrm{eV}$ was used as a reference for correction of the surface charging. A mixture of Gaussian (70\%) and Lorentzian (30\%) functions was used for the least-squares curve fitting procedure. The temperature programmed reduction (TPR), temperature programmed oxidation (TPO), and mass spectrometry were done with a Thermolyne 79300 model tube furnace equipped with an MKS gas analyzer coupled with a quadrupole mass selective detector. The samples were treated with $\mathrm{Ar}$ for $2 \mathrm{~h}$ at $250^{\circ} \mathrm{C}$ before the experiment. In the experiments $10 \%$ vol. $\mathrm{H}_{2}$ in $\mathrm{Ar}$ (for $\mathrm{H}_{2}$-TPR) and $10 \%$ vol. $\mathrm{O}_{2}$ in $\mathrm{Ar}$ (for $\mathrm{O}_{2}$-TPO) mixtures were used at a constant flow rate in the temperature range $50-600^{\circ} \mathrm{C}$ at a ramp of $10^{\circ} \mathrm{C} \min ^{-1}$. The temperature programmed desorption (TPD) experiments were performed with the same Thermolyne 79300 model tube furnace equipped with an MKS gas analyzer coupled with a quadrupole mass selective detector using pure Ar as carrier gas. The sample was used without any pretreatment. The identification of the products and the conversions of alcohol and mesitylene oxidations were measured by gas chromatography-mass spectrometry (GC-MS) methods using a 7820A GC system connected with a thermal conductivity 
detector of 5975 series MSD from Agilent Technologies. A nonpolar cross-linked methyl siloxane column with dimensions of 12 in $\times 0.200 \mathrm{~mm} \times 0.33 \mu \mathrm{m}$ was used. The atomic adsorption spectroscopy (AAS) was measured by a Varian AA-4 updated atomic absorption spectrometer with a deuterium background corrected hollow cathode lamp, at the respective resonance line using an air-acetylene flame.

\subsection{Catalytic Activity Measurements}

Alcohol Oxidation: In a typical alcohol oxidation procedure, alcohol (1.0 mmol), catalyst $(50 \mathrm{mg})$ and toluene $(15 \mathrm{~mL})$ were put in a $50 \mathrm{~mL}$ two-necked round bottom flask. The flask with the reaction mixture with a reflux condenser attached was immersed in a silicon oil bath preheated to the reaction temperature. The reaction mixture was refluxed under vigorous stirring $(700 \mathrm{rpm})$ for the required time under air flow. After reaction, the mixture was cooled, the catalyst was removed by filtration, and GC-MS was used to analyze the filtrate. The conversions were determined based on concentration of alcohols. The selectivities were calculated based on aldehydes or ketones as the only products. Most reactions were repeated at least three times and the average values of conversions were used.

1,3,5-trimethylbenzene Oxidation: In a typical oxidation reaction, 1,3,5-trimethylbenzene (required amount in $\mathrm{mL}$ ) and catalyst $(100 \mathrm{mg})$ were put in a $50 \mathrm{~mL}$ two-necked round bottom flask. The flask with the reaction mixture with a reflux condenser attached was immersed in a silicon oil bath pretreated at $130^{\circ} \mathrm{C}$. The reaction mixture was then heated at $130^{\circ} \mathrm{C}$ under vigorous stirring $(700 \mathrm{rpm})$ for a certain time under air flow. After reaction, the mixture was cooled, the catalyst was removed by filtration, and GC-MS was used to analyze the filtrate. The conversions were determined based on concentration of substrates. The selectivities were calculated based on aldehydes, acids and esters as the products. 


\section{Results}

\subsection{Structural Characterization of cation promoted mesoporous manganese oxides}

Figure 1A and Figure 1B represent the low and the wide angle PXRD patterns of the UCT-18 materials respectively. The low angle diffraction lines, like those of other UCT materials, indicate the existence of an ordered mesostructure. The low-angle PXRD line positions are almost the same for UCT-18 and UCT1 materials (in $\mathrm{nm}$ ) indicating very similar particle sizes (Table 1). According to the model of UCT materials, the low angle diffraction line positions correspond to the average nanoparticle size. The wideangle PXRD patterns suggest an amorphous nature of the materials. The wide-angle PXRD patterns of UCT-18-Cs at different calcinations temperatures are shown in Figure S1. The material is amorphous at low calcination temperatures $\left(<450^{\circ} \mathrm{C}\right)$ and transforms to crystalline bixbyite phase $\left(\mathrm{Mn}_{2} \mathrm{O}_{3}\right)$ at elevated temperatures $\left(>450^{\circ} \mathrm{C}\right.$ ). The $\mathrm{N}_{2}$ adsorption and desorption isotherms (Figure 1C), show Type IV adsorption isotherms, followed by a Type I hysteresis loop, indicating regular mesoporous structures for all materials. The BET surface areas are summarized in Table 1. All the UCT-18 materials exhibit higher surface areas with UCT-18-Na having the maximum $\left(152 \mathrm{~m}^{2} / \mathrm{g}\right)$. The BJH desorption pore size distributions of UCT-18 materials are the same (pore diameter $3.4 \mathrm{~nm}$ ) (Figure 1D, Table 1). The unique features of UCT materials are the expansion of d spacings and pore sizes upon heat treatment, which is the opposite of conventional mesoporous materials, where mesopores shrink upon heat treatment [35]. The cation promoted UCT-18-Cs material shows a similar increase of pore size distributions with rising calcination temperatures. The pore size increased from $3.4 \mathrm{~nm}\left(250^{\circ} \mathrm{C}\right)$ to $7.8 \mathrm{~nm}\left(550^{\circ} \mathrm{C}\right)$ (Table S1, Figure S2). The FE-SEM images of UCT-18 materials (Figure 2A-E) show very similar features with no distinguishable differences. They all show aggregated micron size rounded particles. The HR-TEM images (Figure 2F-H) show aggregated nanoparticles with an average particle size of 10-12 nm and formation of a porous network in between the particles. The higher magnification HR-TEM images (Figure 2B) indicate that the nanoparticles are crystalline. The lattice fringes of $0.49 \mathrm{~nm}$ and $0.27 \mathrm{~nm}$ can 
be indexed to the crystal phase (200) and (222) of the $\mathrm{Mn}_{2} \mathrm{O}_{3}$ (bixbyite). The lack of diffraction in the PXRD can be attributed to the nano-particle nature of the materials. The $\mathrm{Mn} / \mathrm{Cs}(\mathrm{mol} / \mathrm{mol})$ ratio for UCT18-Cs was found to be 3000/1 by ICP-MS, which is quite different from the nominal ratio (Mn/Cs, 100/1, $\mathrm{mol} / \mathrm{mol}$ ), probably excess ions were eliminated by washing.

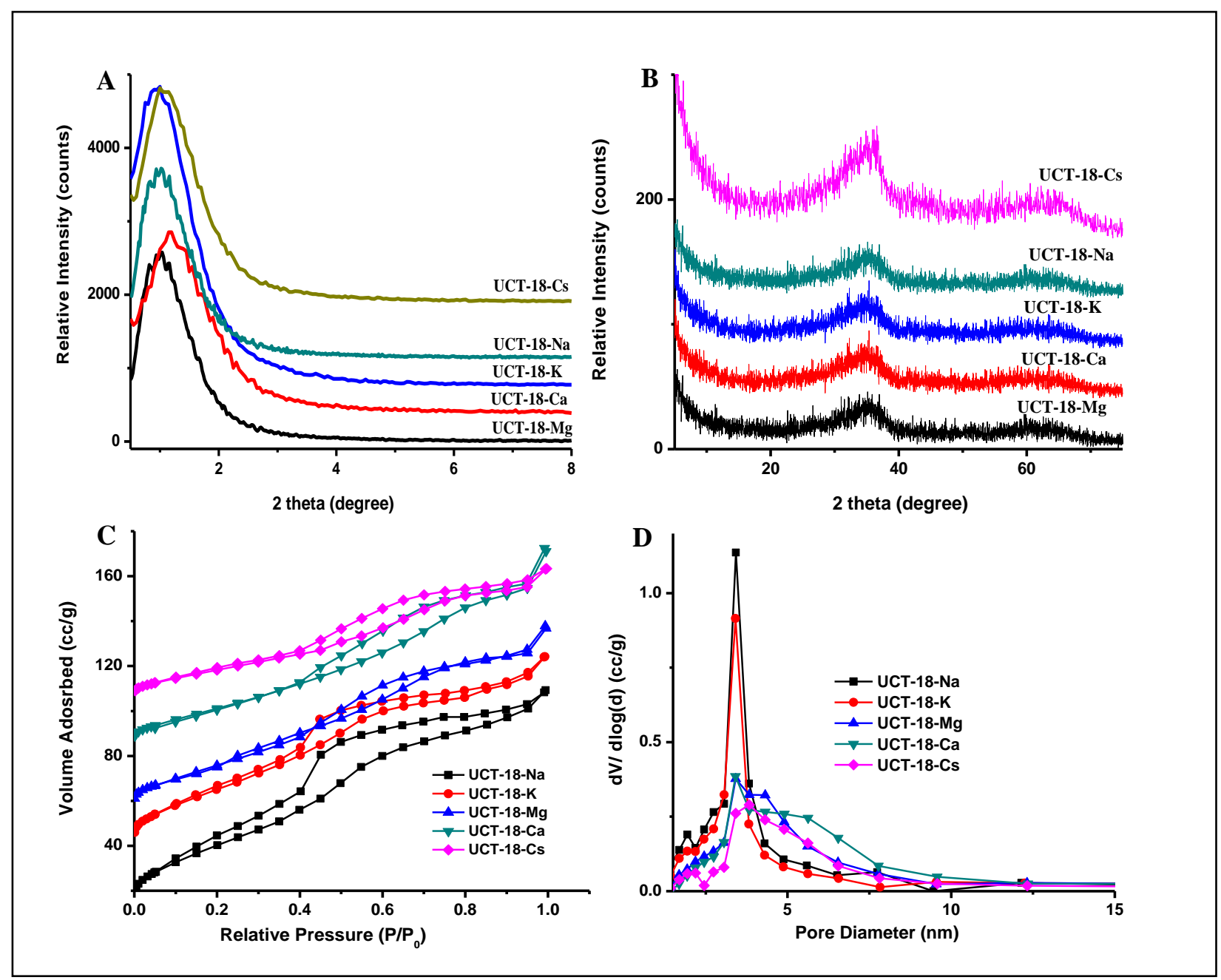

Figure 1. (A) Low angle $\left(0.5^{\circ}-8^{\circ}\right)$ PXRD patterns , (B) Wide angle $\left(5^{\circ}-75^{\circ}\right)$ PXRD patterns, (C) $\mathrm{N}_{2}$ sorption isotherms, and (D) $\mathrm{BJH}$ desorption pore size distributions of cation promoted mesoporous manganese oxides (UCT-18-X, $\mathrm{X}=\mathrm{Mg}^{2+}, \mathrm{Ca}^{2+}, \mathrm{K}^{+}, \mathrm{Na}^{+}$, and $\mathrm{Cs}^{+}$) 
Table 1. Structural parameters of UCT-1 and UCT-18

\begin{tabular}{llcccc}
\hline Metal & Title & $\begin{array}{c}\text { Surface } \\
\text { Area } \\
\left(\mathrm{m}^{2} / \mathrm{g}\right)\end{array}$ & $\begin{array}{c}\text { BJH Desorption } \\
\text { Pore Diameter } \\
(\mathrm{nm})\end{array}$ & $\begin{array}{c}\text { Pore Volume } \\
(\mathrm{cc} / \mathrm{g})\end{array}$ & $\begin{array}{c}\text { Low-Angle PXRD } \\
\text { peak position } \\
(\mathrm{nm})\end{array}$ \\
\hline $\mathrm{Mn}$ & $\mathrm{UCT}-1$ & 200 & 2.8 & 0.153 & 6.7 \\
$\mathrm{Mn} / \mathrm{Cs}$ & $\mathrm{UCT}-18-\mathrm{Cs}$ & 78 & 3.4 & 0.107 & 7.6 \\
$\mathrm{Mn} / \mathrm{Na}$ & $\mathrm{UCT}-18-\mathrm{Na}$ & 152 & 3.4 & 0.192 & 8.5 \\
$\mathrm{Mn} / \mathrm{K}$ & $\mathrm{UCT}-18-\mathrm{K}$ & 149 & 3.4 & 0.161 & 8.5 \\
$\mathrm{Mn} / \mathrm{Ca}$ & $\mathrm{UCT}-18-\mathrm{Ca}$ & 101 & 3.4 & 0.163 & 7.1 \\
$\mathrm{Mn} / \mathrm{Mg}$ & $\mathrm{UCT}-18-\mathrm{Mg}$ & 97 & 3.4 & 0.151 & 8.9 \\
\hline
\end{tabular}

${ }^{\mathrm{a}}$ All materials were calcined at $150^{\circ} \mathrm{C}$ for $12 \mathrm{~h}$, then at $250^{\circ} \mathrm{C}$ for $3 \mathrm{~h}$.
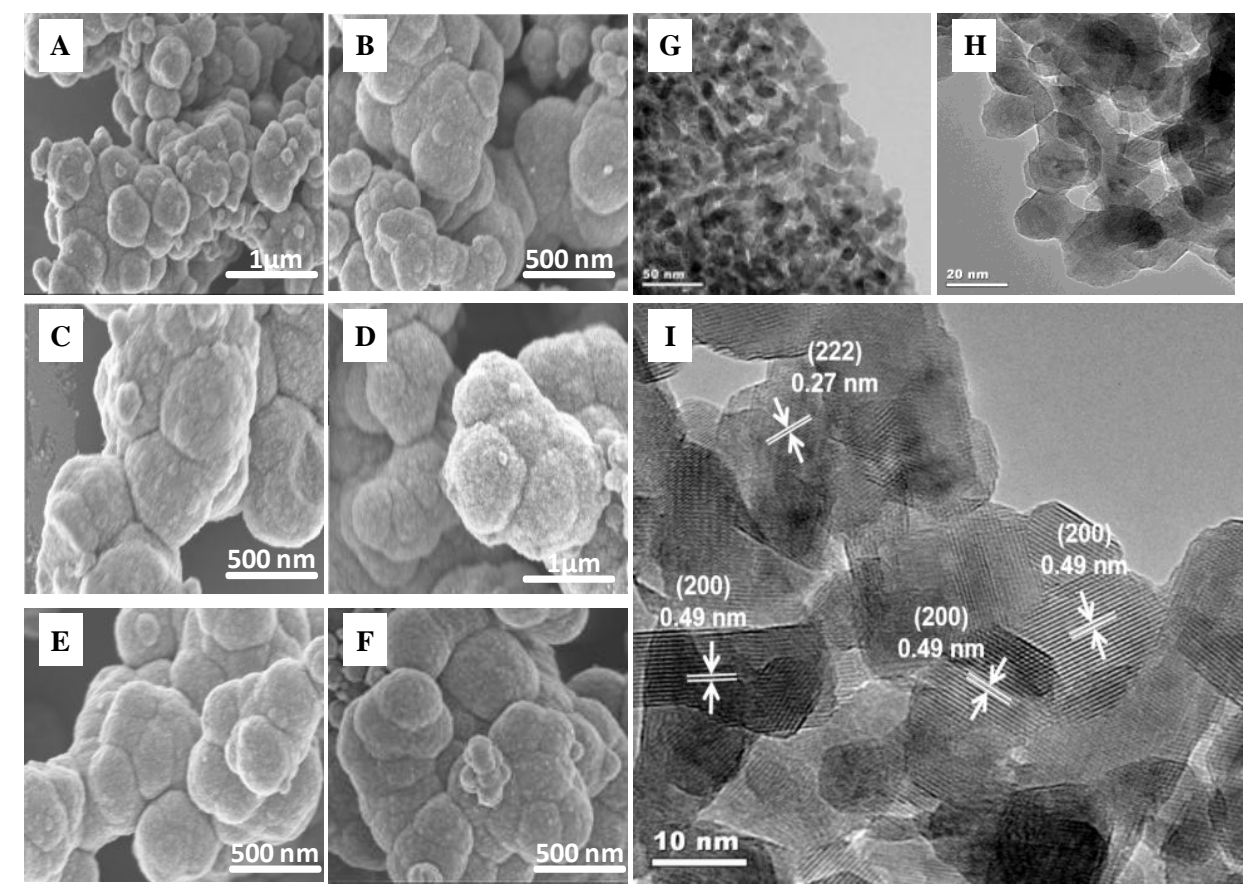

Figure 2. FE-SEM images of (A) UCT-18-Cs, (B) UCT-18-Na, (C) UCT-18-K, (D) UCT-18-Ca, (E) UCT-18-Mg (F) UCT-1 materials and HR-TEM images of UCT-18-Cs material (G, H) at lower magnifications (I) at higher magnification. The measured lattice distances 0.49 and $0.27 \mathrm{~nm}$ are indexed to bixbyite $\mathrm{Mn}_{2} \mathrm{O}_{3}$ (200) and (222) planes

The relative basicity of the materials was determined by $\mathrm{CO}_{2}$ chemisorption studies, because of the known role of basicity in oxidation reactions. The $\mathrm{CO}_{2}$ adsorption isotherms at $298 \mathrm{~K}$ (Figure 3) indicate an increase in basicity with addition of alkali metal ions for the manganese oxide resulting in an increase 
of the adsorbed volume of $\mathrm{CO}_{2}$ being higher for promoted samples. The differences in the adsorbed $\mathrm{CO}_{2}$ volume are more prominent when the temperature of $\mathrm{CO}_{2}$ adsorption was decreased from $298 \mathrm{~K}$ to $198 \mathrm{~K}$. (Figure S3). The initial $\mathrm{CO}_{2}$ uptake (slope) is higher for the promoted samples (UCT-18) suggesting a stronger interaction (chemisorption) between adsorbent and adsorbate $\left(\mathrm{CO}_{2}\right)$. At all temperatures, the UCT-18-Cs material is more basic in nature compared to UCT-1, K-OMS-2 and nonporous commercial $\mathrm{Mn}_{2} \mathrm{O}_{3}$

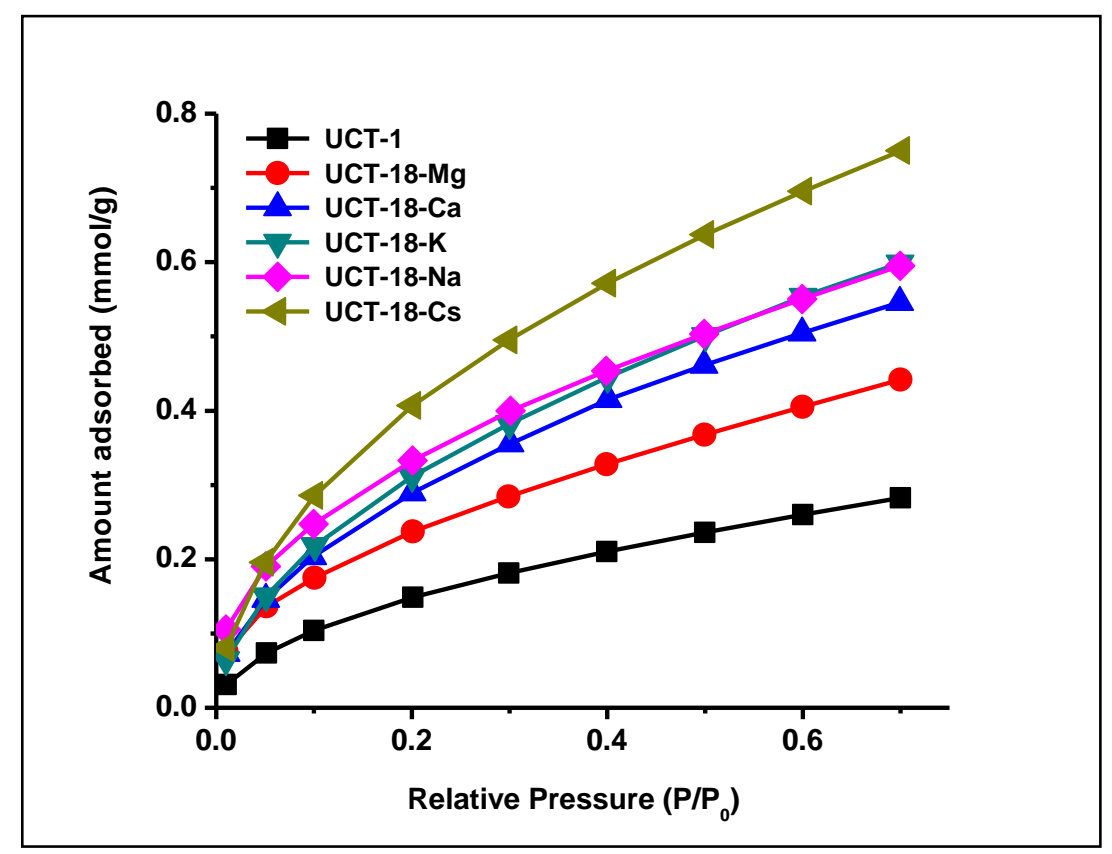

Figure 3. $\mathrm{CO}_{2}$ adsorption isotherms of UCT-1 and UCT-18-X, $\mathrm{X}=\mathrm{Mg}^{2+}, \mathrm{Ca}^{2+}, \mathrm{K}^{+}, \mathrm{Na}^{+}$, and $\mathrm{Cs}^{+}$at $298 \mathrm{~K}$

The structural stabilities of UCT-1 and UCT-18-Cs materials were investigated in a temperature range of $250^{\circ} \mathrm{C}$ to $550^{\circ} \mathrm{C}$ in air by TR-PXRD (Figure $4 \mathrm{~A}$ and $4 \mathrm{~B}$ ). The samples are amorphous, without any crystalline long-range order. Both UCT-1 and UCT-18-Cs materials transform to the bixbyite $\left(\mathrm{Mn}_{2} \mathrm{O}_{3}\right)$ phase with rising temperatures. Interestingly, the addition of trace amounts of $\mathrm{Cs}$ cations $(\mathrm{Mn} / \mathrm{Cs}$, 3000/1) has a marked effect on the crystallization temperature. The non-promoted mesoporous manganese oxide (UCT-1) transform from an amorphous state to a crystalline state around $350^{\circ} \mathrm{C}$, 


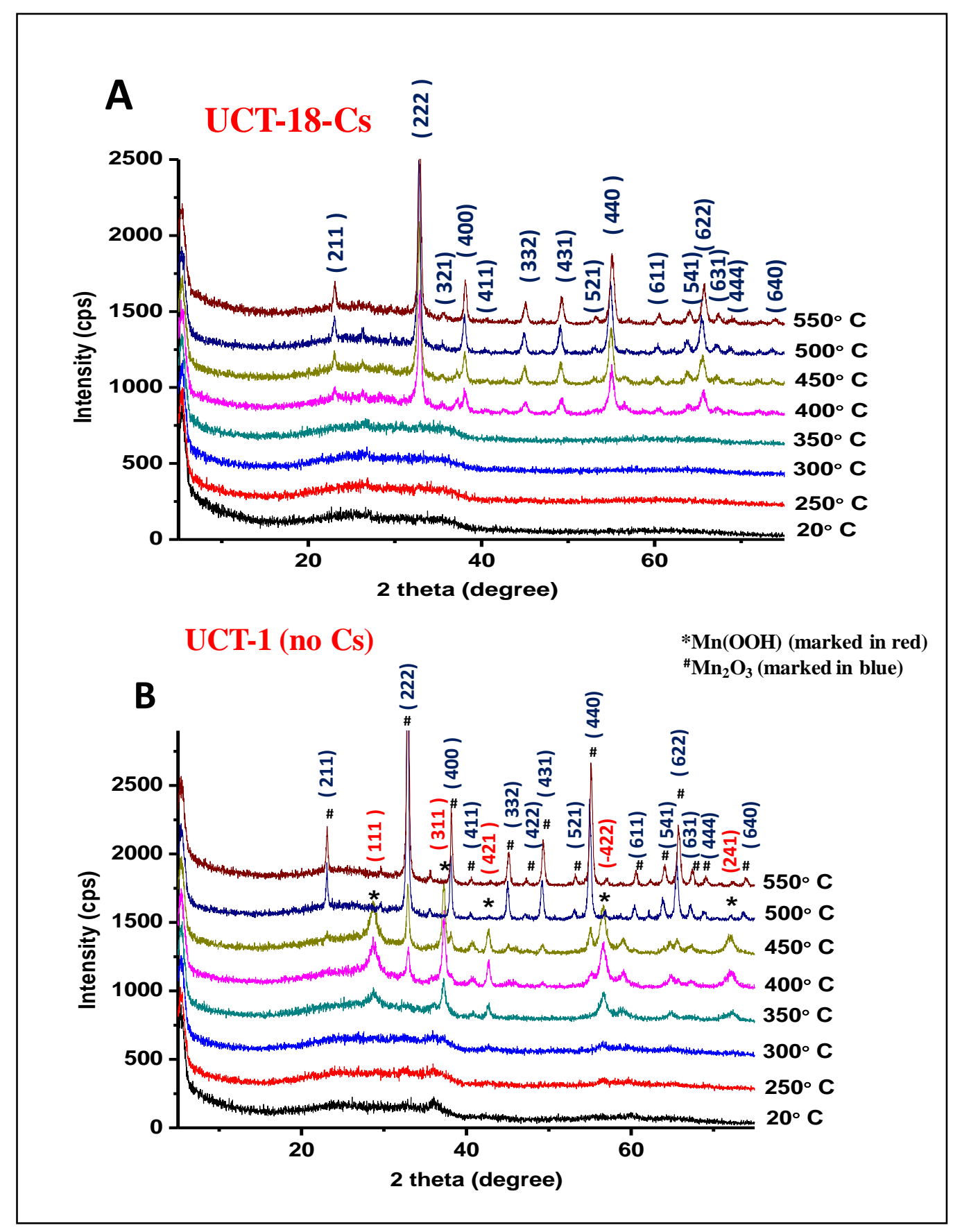

Figure 4. Temperature resolved in situ PXRD (TR-PXRD) of (A) UCT-18-Cs, and (B) UCT-1. The materials were ramped at $5^{\circ} \mathrm{C} \min ^{-1}$ up to $550^{\circ} \mathrm{C}$. The diffraction patterns were obtained in the range of 5$75^{\circ} 2 \theta$ at a scanning rate of $2^{\circ} \mathrm{min}^{-1}$. 
whereas UCT-18-Cs can retain the amorphous state up to $400^{\circ} \mathrm{C}$ before crystallizing directly to the bixbyite $\left(\mathrm{Mn}_{2} \mathrm{O}_{3}\right)$ phase. The oxidation reduction profiles of the materials were tested by the temperature programmed reduction $\left(\mathrm{H}_{2}\right.$-TPR) and oxidation $\left(\mathrm{O}_{2}\right.$-TPO) studies. The two major reduction peaks in the $\mathrm{H}_{2}$-TPR profile (Figure 5A) indicate a two-step reduction $\left(\mathrm{Mn}_{2} \mathrm{O}_{3}\right.$ to $\mathrm{Mn}_{3} \mathrm{O}_{4}$ and $\mathrm{Mn}_{3} \mathrm{O}_{4}$ to $\mathrm{MnO}$ ) [37]. When $\mathrm{Cs}^{+}$is incorporated in the manganese oxide (UCT-18-Cs), clear shifts of reduction temperatures to lower values $\left(280^{\circ} \mathrm{C}, 420^{\circ} \mathrm{C}\right.$ in UCT- 1 and $260^{\circ} \mathrm{C}, 400^{\circ} \mathrm{C}$ in UCT-18-Cs) were observed, which indicate the easy reducible nature of UCT-18-Cs. Whereas, opposite to that of the reduction profile, the oxidation peak shifted to a higher temperature for the UCT-18-Cs $\left(483^{\circ} \mathrm{C}\right)$ with respect to nonpromoted UCT-1 $\left(477^{\circ} \mathrm{C}\right)$ in the $\mathrm{O}_{2}$-TPO profile (Figure 5B). The temperature programmed desorption $\left(\mathrm{O}_{2}-\mathrm{TPD}\right)$ under $\mathrm{Ar}$ was performed to look into the surface oxygen activity of the materials in the oxidation reaction. A major $\mathrm{O}_{2}$ loss from both of the materials was observed $\left(532^{\circ} \mathrm{C}\right.$ for UCT-1 and $570^{\circ} \mathrm{C}$ for UCT-18-Cs) in the $\mathrm{O}_{2}$ TPD (Figure 5C), which can be ascribed to the loss of lattice oxygen near the surface of the material [38].

The XPS measurements were done to investigate the oxidation states of manganese and binding energies of different elements in the materials. The XPS results show that the binding energies (BEs) of Mn fall in the region of BEs of $\mathrm{Mn}^{3+}$ for all the materials with negligible differences [39] (Table S2, Figure S4) which is in good agreement with the $\mathrm{Mn}_{2} \mathrm{O}_{3}$ phase by both $\mathrm{H}_{2}$-TPR and PXRD analyses. The $\mathrm{O} 1 \mathrm{~s}$ region was deconvoluted to three components corresponding to three different oxygen species with distinct binding environments. The first component $\mathrm{O}_{\mathrm{s}}$ is the structural or lattice oxygen. The deconvolution results suggest that the area of the $\mathrm{O}_{\mathrm{s}}$ peak in all the promoted UCT-18 materials have a relatively higher ratio (Table S2) than that in the nonpromoted UCT-1 material. 


\subsection{Catalytic Reactions}

\subsubsection{Oxidation of benzyl alcohol}

The oxidation of benzyl alcohol was selected as a model reaction to evaluate the catalytic performances of ion promoted mesoporous manganese oxides. Figure 6A shows the catalytic activity of $\mathrm{K}^{+}$promoted
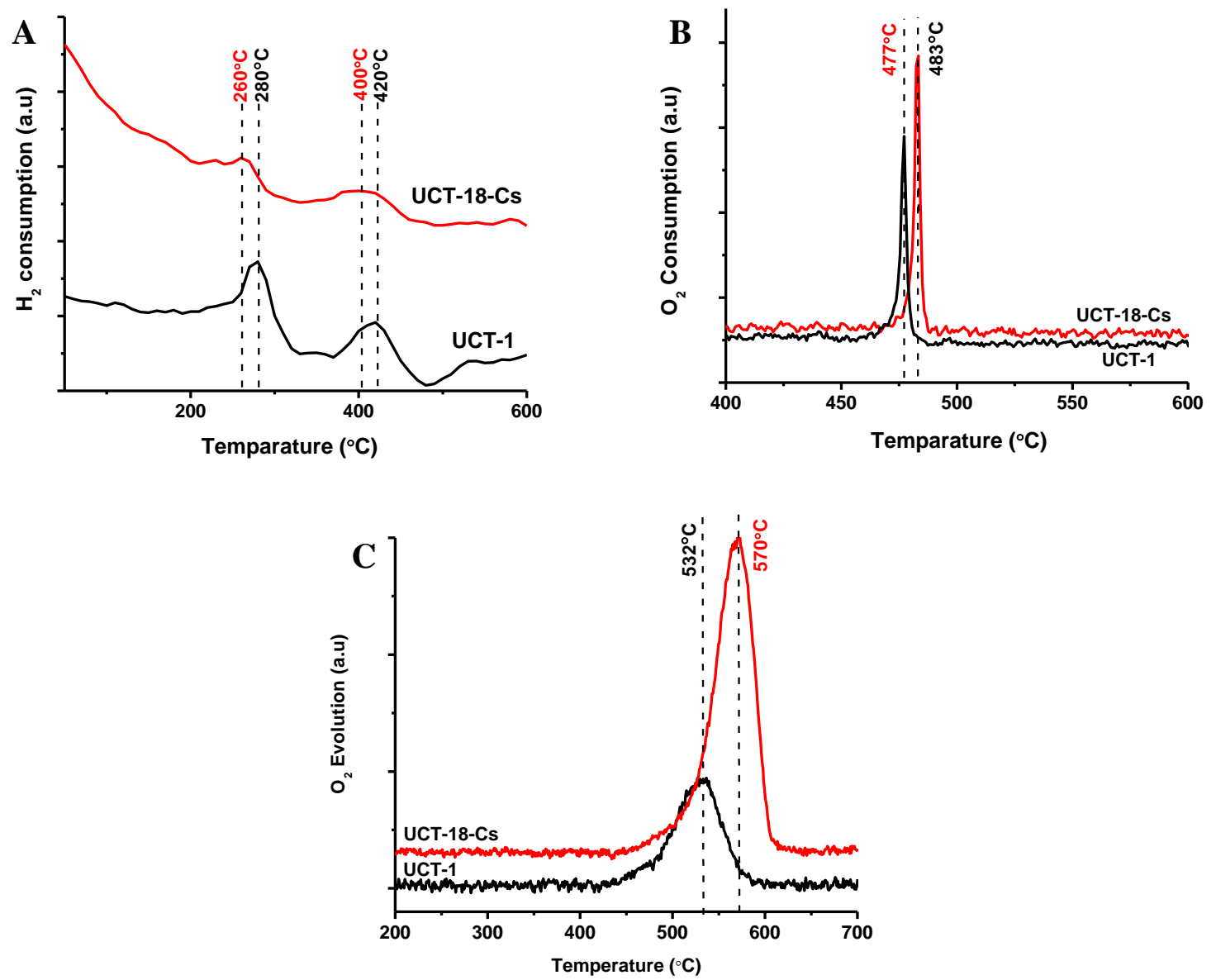

Figure 5. (A) $\mathrm{H}_{2}$-TPR and (B) $\mathrm{O}_{2}$-TPO and (C) $\mathrm{O}_{2}$-TPD profile of UCT-18-Cs and UCT-1. The measurements were conducted from room temperature to $700^{\circ} \mathrm{C}\left(10^{\circ} \mathrm{C} / \mathrm{min}\right)$ under a stream of $10 \%$ $\mathrm{H}_{2} / \mathrm{Ar}$ for $\mathrm{H}_{2}$-TPR, $10 \% \mathrm{O}_{2} / \mathrm{Ar}$ for $\mathrm{O}_{2}$-TPO and pure Ar for $\mathrm{O}_{2}$-TPD with a flow rate of $50 \mathrm{sccm}$.

mesoporous manganese oxide (UCT-18-K), nonpromoted UCT-1 and K-OMS-2 (one of $\mathrm{K}^{+}$promoted state-of-the-art manganese oxide catalysts effective for aerobic alcohol oxidation [40]) under identical 
conditions. The promoted UCT-18-K exhibit higher conversion of benzyl alcohols compared to UCT-1, K-OMS-2 and K-OMS-2 calcined at $150^{\circ} \mathrm{C}$ for $12 \mathrm{~h}+250^{\circ} \mathrm{C}$ for $3 \mathrm{~h}$. The conversion was $100 \%$ at $110^{\circ} \mathrm{C}$

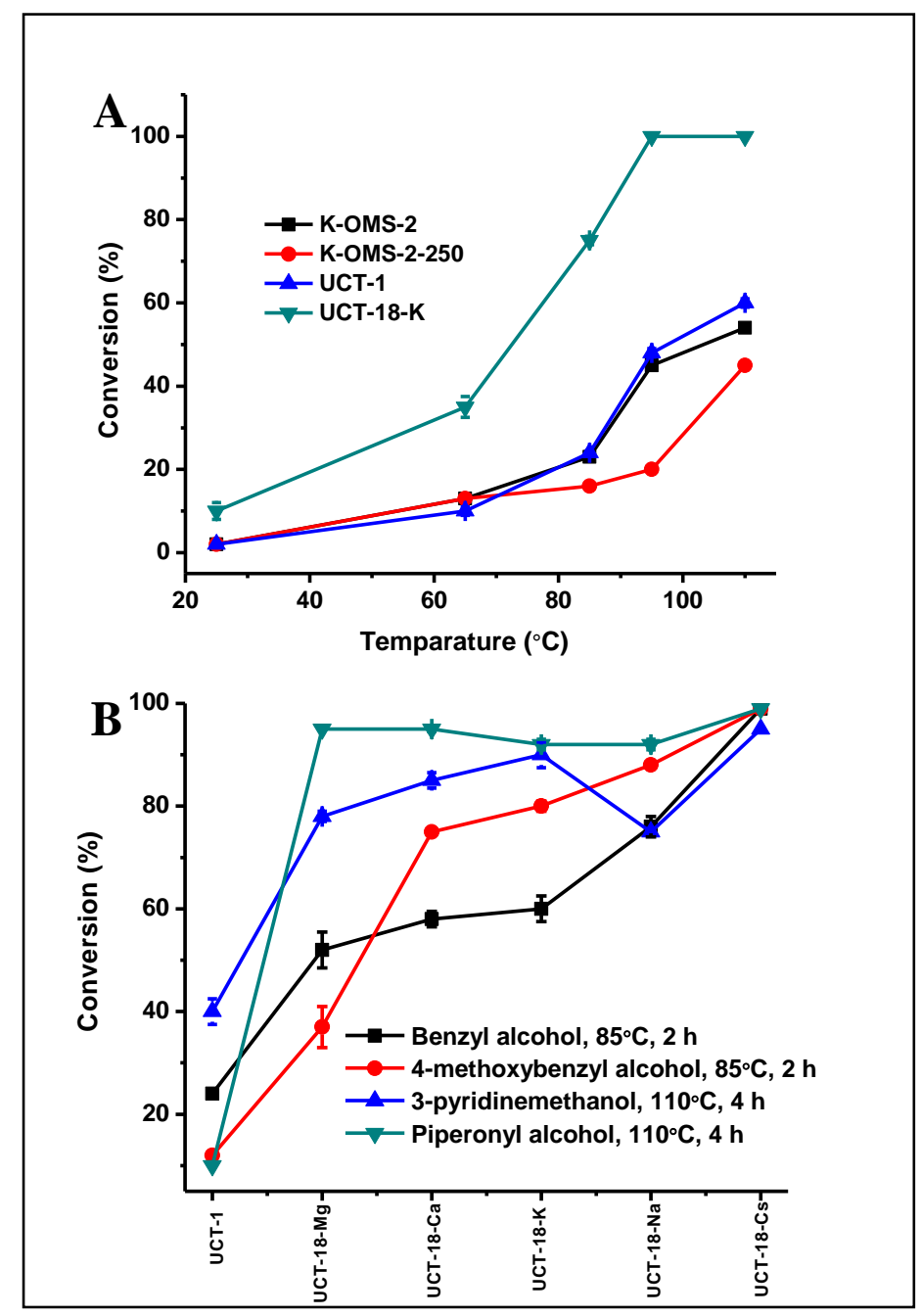

Figure 6. (A) The comparison of activity in benzyl alcohol oxidation at different temperatures. Reaction conditions: benzyl alcohol $(1.0 \mathrm{mmol})$, catalyst $(50 \mathrm{mg})$, toluene $(15 \mathrm{~mL})$, under air flow, $2 \mathrm{~h} .(\mathrm{B})$ The oxidation of alcohols by UCT-1 and UCT-18. Reaction Conditions: alcohols (1.0 mmol), toluene (15 mL), catalyst (50 mg), under air flow, $85^{\circ} \mathrm{C} / 110^{\circ} \mathrm{C}, 2 \mathrm{~h} / 4 \mathrm{~h}$. 
for UCT-18-K. The selectivity in all cases was $100 \%$, as benzaldehyde was the only product observed by GC-MS. To investigate the leaching of ions in solution, the catalyst was removed after the reaction by filtration. The filtrate was tested by AAS, no K or Mn ions were found in the filtrate.

\subsubsection{Catalyst screening}

The cation amount of the materials and the corresponding catalytic activity were also tested. Apart from the nominal Mn/cation (100/1, mol/mol) ratio, the UCT-18-K was also synthesized with different $\mathrm{Mn} / \mathrm{K}$ molar ratios (50/1, 20/1 and 10/1). The $\mathrm{Mn} / \mathrm{K}$ molar ratio 10/1 did not give any clear reaction gel, as the surfactant became insoluble and precipitated. The benzyl alcohol oxidation was done by UCT-18-K with different Mn/K molar ratios (Figure S5). The Mn/K molar ratio 100/1 was found to be optimal. After demonstrating the superior catalytic activity of $\mathrm{K}^{+}$promoted manganese oxide (UCT-18-K) over nonpromoted and other $\mathrm{K}^{+}$promoted manganese oxide (UCT-1, K-OMS-2), other promoted oxides with different alkali metal cations (UCT-18-Mg, UCT-18-Ca, UCT-18-Na, UCT-18-Cs) were prepared. Selective aerobic oxidation of structurally different alcohols was performed to evaluate the catalytic performance of mesoporous UCT-1 and UCT-18 materials. Figure 6B describes the increase of activity with the addition of metal ions for 4 different alcohols. There is a trend of increasing activity observed in the following order UCT-1 <UCT-18-Mg <UCT-18-Ca <UCT-18-K <UCT-18-Na <UCT-18-Cs. This trend in activity is related to both the size and charge of the ions in manganese oxide (higher ratio resulted in higher catalytic activity). The observed trend suggests that the promoted materials are always better than nonpromoted ones and $\mathrm{Cs}$ is the best promoter in the reaction.

\subsubsection{Oxidation of various alcohols}

The UCT-18-Cs (as the most active promoted UCT-18) and non-promoted UCT-1 were selected for the further testing of oxidations of structurally different alcohols. Table 2 summarizes the oxidation of 12 different alcohols catalyzed by the UCT-18-Cs and UCT-1. The UCT-18-Cs catalyst showed significantly 
higher activity for the conversion of all the alcohols to aldehydes or ketones as compared to UCT-1. UCT-18-Cs oxidized various types of structurally different alcohols with almost $100 \%$ conversions.

Table 2. Aerobic selective oxidation of different alcohols by UCT-1 and UCT-18-Cs ${ }^{\mathrm{a}}$

\begin{tabular}{|c|c|c|c|c|c|}
\hline Entry & Substrate & Product & Time $(\mathrm{h})$ & Catalyst & Conversion $^{\mathrm{b}, \mathrm{c}}(\%)$ \\
\hline \multirow{2}{*}{1} & & & $2^{d}$ & UCT 1 & 24 \\
\hline & & & & UCT-18-Cs & $>99$ \\
\hline \multirow{2}{*}{2} & & & $2^{d}$ & UCT 1 & 12 \\
\hline & & & & UCT-18-Cs & $>99$ \\
\hline \multirow[t]{2}{*}{3} & & & $2^{d}$ & UCT 1 & 30 \\
\hline & & & & UCT-18-Cs & $>99$ \\
\hline \multirow[t]{2}{*}{4} & & & 2 & UCT 1 & 85 \\
\hline & & & & UCT-18-Cs & $>99$ \\
\hline \multirow[t]{2}{*}{5} & & & 2 & UCT 1 & 45 \\
\hline & & & & UCT-18-Cs & \\
\hline \multirow[t]{2}{*}{6} & & & 4 & UCT 1 & $\frac{10}{>90}$ \\
\hline & & & & UCT-18-Cs & \\
\hline \multirow[t]{2}{*}{7} & & & 2 & UCT 1 & 40 \\
\hline & & & & UCT-18-Cs & 95 \\
\hline \multirow[t]{2}{*}{8} & & & 2 & UCT 1 & 70 \\
\hline & & & & UCT-18-Cs & 92 \\
\hline \multirow[t]{2}{*}{9} & & & 2 & UCT 1 & 30 \\
\hline & & & & UCT-18-Cs & $>99$ \\
\hline \multirow{2}{*}{10} & & & 15 & UCT 1 & 8 \\
\hline & & & & UCT-18-Cs & 50 \\
\hline \multirow[t]{2}{*}{11} & & & 6 & UCT 1 & 80 \\
\hline & & & & UCT-18-Cs ${ }^{\mathrm{e}}$ & 93 \\
\hline \multirow[t]{2}{*}{12} & & & 15 & UCT 1 & 3 \\
\hline & & & & UCT-18-Cs & 30 \\
\hline
\end{tabular}

${ }^{a}$ Reaction Conditions: alcohols $(1.0 \mathrm{mmol})$, toluene $(15 \mathrm{~mL})$, catalyst $(50 \mathrm{mg}), 110^{\circ} \mathrm{C}$, under air flow.

${ }^{\mathrm{b}}$ Conversion $(\%)$ of alcohols $=[1-($ concentration of alcohols after reaction $) \times($ concentration of alcohols before reaction $\left.)^{-1}\right] \times 100 .{ }^{c}$ Selectivity was $100 \%$, no products other than aldehyde and ketone were found. ${ }^{\mathrm{d}}$ Reactions were performed at $85^{\circ} \mathrm{C}$. ${ }^{\mathrm{e}}$ Selectivity was $92 \%$, the other product was di-aldehyde for UCT18-Cs. 
UCT-18-Cs was capable of oxidizing aromatic [Entry 1-11, Table 2], aliphatic [Entry 12, Table 2], primary [Entry 1-8, Table 2] and secondary [Entry 9, Table 2] alcohols selectively into the corresponding carbonyl compounds. For long chain aliphatic alcohol [Entry 12, Table 2] the conversion was less and a longer reaction time was required. The alcohols containing $\mathrm{S}$ and $\mathrm{N}$ as heteroatoms [Entry 7, 8, Table 2] were converted to the corresponding aldehydes selectively. In the case of oxidation of piperonyl alcohol [Entry 6, Table 2] to piperonyl aldehyde, the UCT-18-Cs had ten times better conversion than UCT-1. The UCT-18-Cs converted 1,3-Benzenedimethanol chemoselectively (92\% selectivity) to monoaldehyde with $93 \%$ conversion [Entry 11, Table 2].

\subsubsection{The Effect of air and solvent, calcination temperatures and comparison with conventional catalysts}

The selective oxidation of alcohols was performed under air, which is considered to be a mild oxidant. In order to investigate the role of air as an oxidant, a model reaction (benzyl alcohol oxidation) was performed under $\mathrm{N}_{2}$. The conversion decreased significantly $\left(30 \%\right.$ at $\left.85^{\circ} \mathrm{C}\right)$ compared to that of the reaction done under air $\left(>99 \%\right.$ at $\left.85^{\circ} \mathrm{C}\right)$. A significant decrease of conversion $\left(10 \%\right.$ at $85^{\circ} \mathrm{C}, 100 \%$ selectivity) was observed again, when acetonitrile was used as solvent instead of toluene. To evaluate the reusability, the UCT-18-Cs catalyst was removed by filtration, washed with reaction solvent (toluene) and excess ethanol, dried under vacuum and reactivated at $250^{\circ} \mathrm{C}$ for $2 \mathrm{~h}$ prior to each catalytic cycle. The UCT-18-Cs exhibited only a slight catalytic activity loss compared to the fresh catalyst (> 99\% conversion, $100 \%$ selectivity) even after the $4^{\text {th }}$ reuse (90\% conversion, 100\% selectivity) (Figure 7A). To study the effect of pore size, a model reaction (benzyl alcohol oxidation) was performed using UCT18-Cs and UCT-1 calcined at different temperatures (Figure 7B). The UCT-18-Cs was more active than UCT-1 despite the overall decrease of activity with rising calcination temperatures. Kinetic experiments were performed for oxidation of benzyl alcohol at $85^{\circ} \mathrm{C}$ with UCT-18-Cs. A first order dependence of the alcohol concentration on rate was observed from the liner relationship of $\ln$ [alcohol] vs time with a rate 
constant of $0.026 \mathrm{~min}^{-1}$ (Figure S6). Commercial $\mathrm{Mn}_{2} \mathrm{O}_{3}$ and K-OMS-2 were also tested for oxidation of 1-Decanol for comparison (Table S3). The UCT-18-Cs material was found to be much more active (30\% conversion) than UCT-1 (3\% conversion), nonporous commercial $\mathrm{Mn}_{2} \mathrm{O}_{3}(0 \%$ conversion) and K-OMS-2 (15\% conversion). The conversions for UCT-18-Cs were very high and selective to the carbonyl with no over- oxidation (to carboxylic acid).

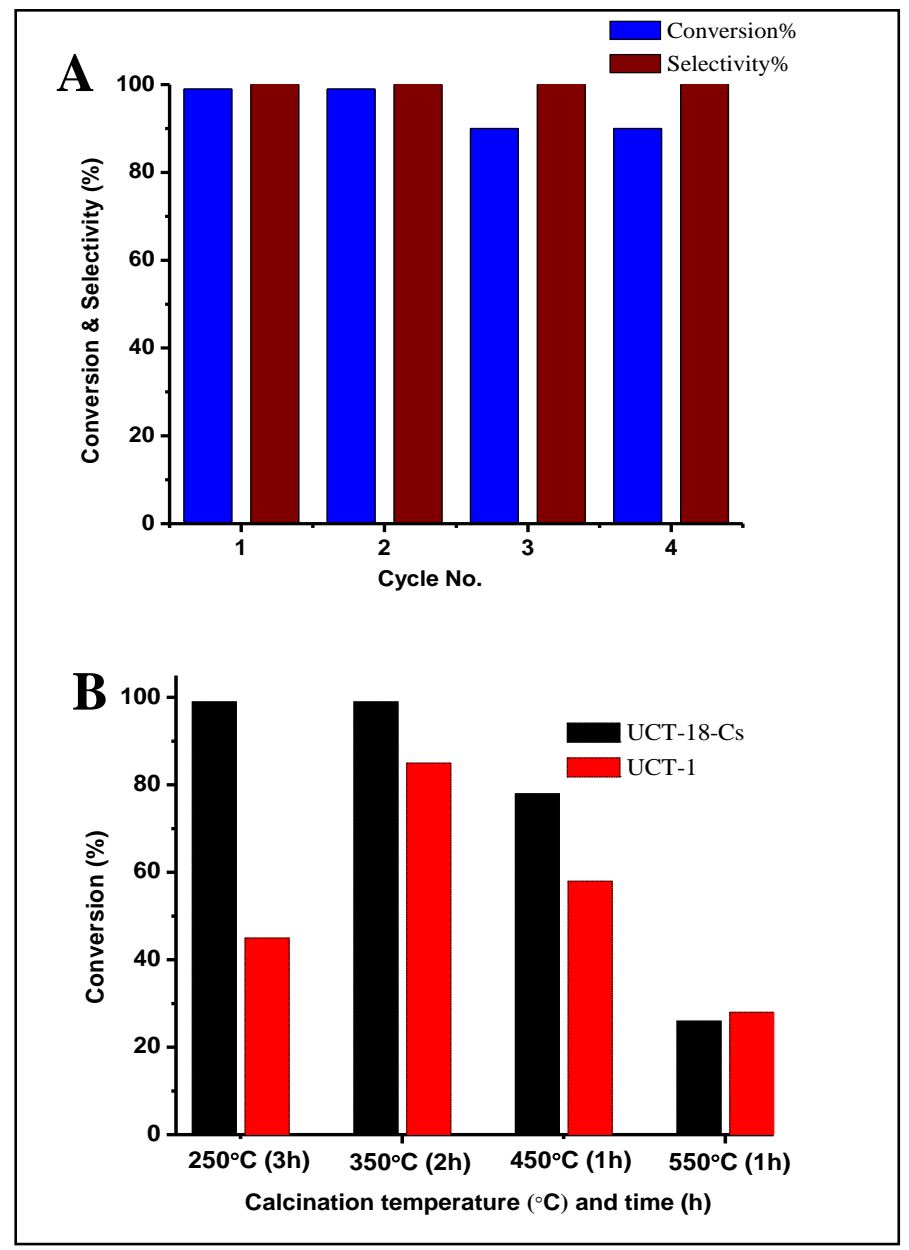

Figure 7. (A) Reusability of UCT-18-Cs in benzyl alcohol oxidation. Reaction conditions: benzyl alcohol (1.0 mmol), UCT-18-Cs $(50 \mathrm{mg})$, toluene $(15 \mathrm{~mL}), 85^{\circ} \mathrm{C}$, under air flow, $2 \mathrm{~h}$. (B) Effect of Calcination temperature on UCT-1 and UCT-18-Cs in alcohol oxidation. Reaction conditions: benzyl alcohol (1.0 mmol), UCT-18-Cs $(50 \mathrm{mg})$, toluene $(15 \mathrm{~mL}), 110^{\circ} \mathrm{C}$, under air flow, $2 \mathrm{~h}$. 


\subsubsection{The oxidation of $1,3,5$-trimethylbenzene (C-H activation)}

The UCT-18-Cs was investigated further for the activation of relatively inert C-H bond. 1,3,5trimethylbenzene (mesitylene) was used as substrate. The UCT-18-Cs catalyst successfully oxidized

Table 3. Aerobic oxidation and cross dehydrogenative coupling of 1,3,5-timethylbenzene (different amounts) by UCT-18-Cs ${ }^{\mathrm{a}}$

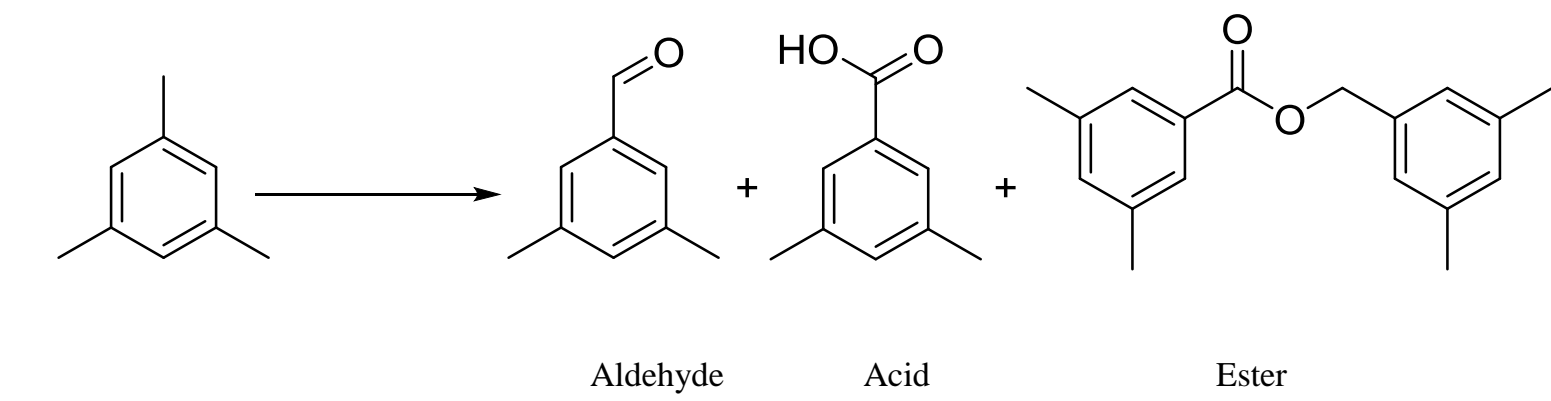

\begin{tabular}{|c|c|c|c|c|c|c|c|}
\hline \multirow[t]{2}{*}{ Entry } & \multirow[t]{2}{*}{ Catalyst } & \multirow[t]{2}{*}{ Amount (mL) } & \multirow{2}{*}{$\begin{array}{l}\text { Time } \\
\text { (h) }\end{array}$} & \multirow{2}{*}{$\begin{array}{c}\text { Conversion } \\
(\%)\end{array}$} & \multicolumn{3}{|c|}{ Selectivity $^{\mathrm{c}}(\%)$} \\
\hline & & & & & Aldehyde & Acid & Ester \\
\hline 1 & UCT-18-Cs & $5(35 \mathrm{mmol})$ & 36 & 95 & nd & 88 & 12 \\
\hline 2 & UCT-18-Cs & $10(70 \mathrm{mmol})$ & 40 & 99 & 1 & 90 & 9 \\
\hline 3 & UCT-18-Cs & $25(175 \mathrm{mmol})$ & 72 & 91 & nd & 91 & 9 \\
\hline 4 & UCT-1 & $10(70 \mathrm{mmol})$ & 40 & 52 & 7 & 69 & 24 \\
\hline
\end{tabular}

${ }^{a}$ Reaction Conditions: 1,3,5-trimethylbenzene (required amount in $\mathrm{mL}$ ), catalyst $(100 \mathrm{mg}), 130^{\circ} \mathrm{C}$, air flow. ${ }^{\mathrm{b}}$ Conversion $(\%)$ of 1,3,5-trimethylbenzene $=[1$-(concentration of 1,3,5-trimethylbenzene after reaction $\left.) \times(\text { concentration of } 1,3,5 \text {-trimethylbenzene before reaction })^{-1}\right] \times 100 .{ }^{c}$ Selectivity $(\%)$ of product $=\left[(\right.$ concentration of product $\left.) \times(\text { total concentration of all products })^{-1}\right] \times 100$. nd $=$ not detected $(<1 \%)$. The Entries signify the high catalytic performance of the catalyst in different scale of the reactant (1,3,5-trimethylbenzene). 
1,3,5-trimethylbenzene (10mL) to 3,5-dimethylbenzoic acid with a very high conversion (99\%) and selectivity (90\%) under aerobic and solvent free conditions (Table 3). Once again, the UCT-18-Cs (99\% conversion) demonstrated enhanced catalytic performance over UCT-1 (52\% conversion) [Entry 4, Table 3] under similar conditions. The UCT-18-Cs also exhibited a high conversions (95\%) and selectivity ( $\sim 90 \%)$ with different scale of reactants $(5 \mathrm{~mL}, 25 \mathrm{~mL})$ [Entry 2-3, Table 3]. The oxidation of 1,3,5-trimethylbenzene also produced (3,5-dimethylphenyl)methyl ester ( $10 \%$ selectivity) via cross dehydrogenative coupling. The oxidation was also conducted with different catalyst amounts (Table S4). Using $100 \mathrm{mg}$ catalyst gave the highest conversion and selectivity, while the lower catalyst loading (25 $\mathrm{mg}, 50 \mathrm{mg}$ ) gave larger amounts of 3,5-dimethylbenzyl alcohols and 3,5-dimethylbenzaldehyde side products along with acid and ester. These results give valuable information about the intermediates in the oxidation of 1,3,5-trimethylbenzene. The reaction is initiated by the formation of alcohols followed by oxidation to the aldehyde, acid and esters. Moreover, the oxidation of 1,2,4-trimethylbenzene produced two different isomeric acids and three different isomeric benzylic esters with a very high conversion (94\%) and selectivity (60/30, acids/esters) (Table S5).

\section{Discussion:}

In this work, alkali ion promoted mesoporous manganese oxide catalysts (UCT-18, University of Connecticut mesoporous materials) were designed for liquid phase oxidation reactions. In the synthesis of UCT-18, Mn precursors along with the other ionic sources were confined in inverse surfactant (P123) micelles, which were then packed to form mesoporous materials. The uncontrolled aggregation of oxoclusters was prevented by surfactant molecules in the reverse micelles and the interface modifier (1Butanol). The hydrotropic nitrate ion increased the solubility of the surfactants by decreasing the aggregation number. The nitrate ions penetrated into the micelles to hydrate it and pulled the positively charged oxo clusters into the micelles [41]. The reaction was driven by evaporation of the solvent at $120^{\circ} \mathrm{C}$ and thermal NOx formation (from the nitrate ion) to control the sol-gel chemistry of Mn sols. The surfactants in the resulting materials were washed off with ethanol (solvent extraction). The mesopores 
were formed by connected inter-particle voids. The chemisorbed nitric oxides and carboxylates were removed from the structure by heating the material at $150^{\circ} \mathrm{C}$ for $12 \mathrm{~h}$ and $250^{\circ} \mathrm{C}$ for $3 \mathrm{~h}$ under air [35].

Despite the promoter ions being mentioned several times in the literature, their major role in catalytic reactions is still unclear [42-45]. A trend of increasing catalytic activity with the increasing size/charge ratio of promoter cations has not been previously observed. One possible explanation concerning the role of promoter ions in the enhanced catalytic activity is the alteration of the surface basicity. Alkali metal ions on the surface of the oxides are known to increase the basicity of the material due to their electropositive nature [46]. The basic sites can be considered either as defects in the material or as enhanced electron density of the framework oxygen due to the presence of electropositive cations [47]. The effect of surface Cs causes the binding energy of lattice oxygen to decrease in energy as discussed by Santos et al, which also correlates with the increase of surface basicity [7]. The presence of basic sites on the manganese oxide materials promote the dehydration step by aiding the deprotonation of the alcohol, which is an important step for partial oxidation [48]. The basicity of the materials also promotes the oxidation of alkylbenzenes [49]. Therefore, increasing the basicity of mesoporous manganese oxide by incorporating alkali metal ions can enhance the catalytic activity for oxidation and esterification. In this work trace amounts of alkali metal ions (Mn/ion, >1000/1) were incorporated in the manganese oxide materials. However, the ions caused a remarkable increase in the catalytic activity towards oxidative transformations.

The relative basicites of materials were evaluated by $\mathrm{CO}_{2}$ chemisorption experiments (Figure 3). There is a trend of increasing basicity for the promoted materials, which correlates with the size/charge ratio of the cations. Like the trend observed for the oxidation of different alcohols (Figure 6B), a similar trend was observed for the basicity of the materials, with Cs promoted material being the most basic. The UCT-18Cs also exhibited higher basicity than nonpromoted UCT-1, other active promoted manganese oxides (KOMS-2), and commercial nonporous $\mathrm{Mn}_{2} \mathrm{O}_{3}$ at different temperatures. Therefore, the basicity of the 
promoted materials plays an important role in the higher activity in oxidation of alcohols and alkylbenzenes. Despite the fact that adding base in the reaction can increase the activity in oxidation in many systems, an efficient oxidation process should not involve any additives such as base or acid [50]. The bifuctional nature (redox and basic) of UCT-18-Cs can enhance the oxidation activity without any additional base. The results from Table S6 show that adding base in the system with the nonpromoted material (UCT-1) did not form acid or ester products. Therefore, the bifucntional nature is believed to be playing a role in both oxidation of 1-Decanol to 1-Decanoic acid and esterification of 1-Decanoic acid and 1-Decanol .

The UCT-18-Cs material shows an increase of pore size with rising calcination temperatures (Table S1, Figure S2) due to the increase of nanoparticle size and intra particle voids (mesopores). Smaller particle sizes and higher surface areas provide more surface defects, which in turn act as active sites [51, 52]. Hence the decrease of surface area with heat treatment can be the reason behind the reduction of catalytic activity (Figure 7B). The UCT-18-Cs is also found to be more active in the amorphous state than in the pure crystalline state, despite exhibiting higher activity than UCT-1 for all different states of the materials. The TR-PXRD (Figure 4) data indicate that the amorphous state is more stable for UCT-18-Cs than UCT-1 with heat treatment. The higher catalytic activity of promoted UCT-18-Cs compared to nonpromoted UCT-1 can also be attributed to the retention of the amorphous state. Manganese oxides in the amorphous states are known to be more active than in crystalline states $[13,14,53]$. The labile lattice oxygen of manganese oxide is one of the reasons for enhanced catalytic activity of amorphous manganese oxides [54]. The lack of crystallinity in the amorphous state of the materials promotes a more available supply of lattice oxygen. The smaller particle sizes and higher surface areas of the amorphous materials are other contributing factors. 
The activity of the manganese oxides can be linked to the ease of reducibility of the materials. The low reduction temperatures of promoted UCT- 18 - $\mathrm{Cs}\left(280^{\circ} \mathrm{C}, 420^{\circ} \mathrm{C}\right.$ in UCT- 1 and $260^{\circ} \mathrm{C}, 400^{\circ} \mathrm{C}$ in UCT- 18 $\mathrm{Cs}$ ), as observed in $\mathrm{H}_{2}$-TPR studies (Figure 5A) indicate an increase of mobility and accessibility of lattice oxygen. The presence of $\mathrm{Cs}^{+}$induces a more facile supply of lattice oxygen, which can create defects in the materials [7]. The defects promote the adsorption of the substrate, and high adsorption capacity of the mesoporous materials is a well established property [55]. The effect on lattice oxygen was more prominently observed in the $\mathrm{O}_{2}$-TPD studies (Figure 5C). The UCT-1 and UCT-18-Cs evolve lattice oxygen at around $532^{\circ} \mathrm{C}$ and $570^{\circ} \mathrm{C}$ respectively. Though these materials are amorphous in nature they still have some crystallinity with a framework structure as observed in HR-TEM images. So the term lattice (or bulk) oxygen can be used for the amorphous UCT-1 and UCT-18-Cs materials. The involvement of lattice oxygen in the catalytic activity suggests that the reaction goes through the MarsVan-Krevelen mechanism [56-59]. The $\mathrm{Mn}^{3+}$ species disproportionates to $\mathrm{Mn}^{2+}$ and $\mathrm{Mn}^{4+}$ species under oxidative conditions [60]. The adsorbed alcohol molecules are oxidized with multi-electron transfer between the Mn centers (Scheme S1). The reduced Mn species however can get oxidized by labile lattice oxygen with creation of oxygen vacancies. The resulting oxygen vacancies are finally replenished by gas phase oxygen molecules. The presence of three different oxygen species in different binding environments was established by XPS studies (Table S2). The areas of $\mathrm{O}_{\mathrm{s}}$ peaks (structural or lattice oxygen) in all the promoted UCT-18 materials are relatively higher than nonpromoted UCT-1. Therefore, the easily reducible best promoted UCT-18-Cs evolve labile lattice oxygen more readily by creating active sites, which is related to the enhanced catalytic activity.

Selective oxidation of several different alcohols were performed by nonpromoted (UCT-1) and promoted (UCT-18) mesoporous manganese oxides. The activity followed the series of cations according to the size/charge ratio, UCT-1 <UCT-18-Mg <UCT-18-Ca <UCT-18-K <UCT-18-Na <UCT-18-Cs. Among the promoted oxides, the Cs promoted one performed best. The Cs promoted material (UCT-18-Cs) was then used for oxidation of 12 different alcohols to corresponding aldehydes and ketones. The reaction 
exhibited very high conversion (> 99\% in most cases) in most cases under mild aerobic conditions. Only in the case of big and inactive 1-Decanol [Entry 12, Table 2] the conversion was less. This may be due to the limitation of molecular transportation in the mesopores of the catalyst or the inactivity of the long chain aliphatic alcohol. Transition metal oxide based catalysts are notorious for not being ideal types of heterogeneous catalysts for the selective oxidation of alcohols containing heteroatoms (i.e. S and N), because the strong coordination of the heteroatom with the metal center results in deactivation of the catalyst [61]. However, UCT-18-Cs successfully and selectively catalyzed the alcohols containing S and $\mathrm{N}$ as heteroatoms [Entry 7, 8, Table 2] to the corresponding aldehydes. Moreover the recovered catalyst (UCT-18-Cs) gave conversions similar to the fresh catalysts in the case of oxidation of 2thiophenemethanol. The excellent selectivity in the oxidation reactions can be attributed to the observations that aldehydes and ketones are the only products with no over-oxidation to carboxylic acids occurring. The catalytic performance of UCT-18-Cs can be restored by washing with toluene and methanol followed by reactivation at $250^{\circ} \mathrm{C}$ for $2 \mathrm{~h}$ in air. The reactivation is required to remove adsorbed species from the surface of the catalyst. The first order dependence of rate on alcohol concentration is also an indication of the rate determining step, which could involve adsorption of alcohols or desorption of aldehydes from the active sites of the catalyst surface. The lower activity under $\mathrm{N}_{2}(30 \%$ conversion) compared to air (> 99\% conversion) is attributed to adsorbed oxygen on the catalyst surface and labile lattice oxygen. These observations also indicate the role of air in the oxidation reaction, as the loss of lattice oxygen is replenished by the oxygen coming from air [59]. The significantly reduced conversion ( $10 \%$ in acetonitrile) in polar solvent may be due to competitive binding of the solvents to the active sites of the catalyst [59]. The reaction in acetonitrile (100\% selectivity for benzaldehyde, no other products were detected) also rules out the formation of toluene due to non oxidative disproportionation reaction of benzyl alcohol $[62,63]$ in the reaction condition. The oxidation of the solvent, toluene (without the substrate) was carried out under identical conditions by UCT-18-Cs to verify if benzaldehyde was formed as a result of oxidation of toluene. The trace amount of benzaldehyde $(<1 \%)$ formed after $15 \mathrm{~h}$ of reaction indicates that UCT-18-Cs selectively catalyzed the oxidation of alcohols in the mentioned reaction 
conditions. The oxidation of aromatic $\mathrm{C}-\mathrm{H}$ bond required prolonged reaction time with a greater amount of catalyst. The relative activity of UCT-18-Cs to inactivated compounds is quite notable. For example, the oxidation of the inactivated long chain alcohol 1-Decanol to 1-Decanal shows a performance of UCT18-Cs being better than nonpromoted UCT-1, K-OMS-2 (Table S3). Moreover, UCT-18-Cs can undergo solvent free green oxidation of inert 1,3,5-trimethylbenzene to 3,5-dimethylbenzoic acid with very high conversion (> 90\% conversion) and selectivity (90/10, acid/ester). This kind of green oxidation under mild and aerobic conditions has not been observed before. Even in the case of large scale transformation, the catalyst exhibited similar conversions and selectivities, (Table 3). The reaction also yielded (3,5dimethylphenyl)methyl ester along with the acid. Formation of the ester is due to cross dehydrogenative coupling (CDC) of 1,3,5-trimethylbenzene or any other intermediates like corresponding alcohols, aldehydes or acids. Typical catalysts used for the cross dehydrogenative coupling contain metal centers like $\mathrm{Ru}, \mathrm{Rh}, \mathrm{V}, \mathrm{Cu}$ with basic additives and TBHP as the oxidant [64-67]. The bifunctional nature of UCT-18-Cs (redox and basic) can promote the formation of esters under ambient aerobic and green conditions without the presence of base or expensive oxidants.

\section{Conclusion:}

To summarize, the incorporation of trace amounts (Mn/ion, >1000/1) of alkali metal ions leads us to promoted mesoporous manganese oxides. The cation promoted materials (UCT-18) exhibited regular mesoporosity with pore sizes of $3.4 \mathrm{~nm}$. These catalysts demonstrated other characteristic features of UCT materials (one low angle diffraction line, Type IV isotherm, aggregation of rounded micron size nanoparticles). The cation promoted mesoporous manganese oxides exhibited high catalytic performance for oxidation of alcohols to carbonyl compounds under mild aerobic reaction conditions in the following order UCT-1 <UCT-18-Mg <UCT-18-Ca <UCT-18-K <UCT-18-Na <UCT-18-Cs. The order followed the size/charge ratios of the incorporated cations, which correlates with the increase of relative basicity of the materials. The Cs promoted mesoporous manganese oxide was found to be the most active for 
selective alcohol oxidation reactions (> 95\% conversion in most cases, 100\% selectivity). The UCT-18Cs material demonstrated superior catalytic activity in the solvent free green oxidation of 1,3,5trimethylbenzene to 3,5-dimethylbenzoic acid and (3,5-dimethylphenyl)methyl ester with very high conversions (> 90\% conversion) and selectivity (90/9, acid/ester). Such scalable, green and mild aerobic oxidation and cross dehydrogenative coupling of relatively inert $\mathrm{C}-\mathrm{H}$ bonds was observed for the first time. The enhancement in catalytic activity can be correlated to the bifunctional (redox and basic) nature of the material, which in turn correlates with the promoting effect of ions in the mesoporous manganese oxides. The easily reducible nature with retention of the amorphous phase reflects the greater amount of accessible lattice or structural oxygen, which also contribute to the enhanced catalytic activity. The use of mild reaction conditions, (use of air as the oxidant, at ambient pressure), excellent reusability and high activity towards inactive compounds make the UCT-18 (especially UCT-18-Cs) materials a new class of environmentally friendly oxidation catalysts. The tunable pore size and crystallinity through simple heating cycles make the materials more ubiquitous and this opens a new avenue for the design and application of heterogeneous catalysts.

\section{ACKNOWLEDGMENT}

This work was supported by the U. S. Department of Energy, Office of Basic Energy Sciences, Division of Chemical, Biological, and Geological Sciences under grant DE-FGO2-86ER13622.A000. We also thank Christopher Perkins of the Center for Environmental Sciences and Engineering, University of Connecticut, Storrs for assistance on ICP-MS and Dr. Frank Galasso and David Kriz for helpful discussions. 


\section{References}

[1] C. Kresge, M. Leonowicz, W. Roth, J. Vartuli, Nature 359 (1992) 710-712.

[2] A. Corma, Chem. Rev. 97 (1997) 2373-2420.

[3] A. Taguchi, F. Schüth, Microporous Mesoporous Mater. 77 (2005) 1-45.

[4] Y. Rao, D.M. Antonelli, J. Mater. Chem. 19 (2009) 1937-1944.

[5] A.S. Poyraz, S. Biswas, H.C. Genuino, S. Dharmarathna, C.H. Kuo, S.L. Suib, ChemCatChem 5 (2013) 920-930.

[6] A. Grirrane, A. Corma, H. García, Science 322 (2008) 1661-1664.

[7] V. Santos, M. Pereira, J. Órfão, J. Figueiredo, Appl. Catal. B: Environ 88 (2009) 550-556.

[8] N. Patel, R. Fernandes, A. Miotello, J. Catal. 271 (2010) 315-324.

[9] Z.-R. Tian, W. Tong, J.-Y. Wang, N.-G. Duan, V.V. Krishnan, S.L. Suib, Science 276 (1997) 926-930.

[10] S.L. Suib, J. Mater. Chem. 18 (2008) 1623-1631.

[11] S.L. Brock, N. Duan, Z.R. Tian, O. Giraldo, H. Zhou, S.L. Suib, Chem. Mater. 10 (1998) 26192628.

[12] T. Oishi, K. Yamaguchi, N. Mizuno, ACS Catal. 1 (2011) 1351-1354.

[13] J. Hu, K. Sun, D. He, B. Xu, Chin. J. Catal. 28 (2007) 1025-1027.

[14] A. Iyer, J. Del-Pilar, C.K. King'ondu, E. Kissel, H.F. Garces, H. Huang, A.M. El-Sawy, P.K. Dutta, S.L. Suib, J. Phys. Chem. C 116 (2012) 6474-6483.

[15] X. Li, J. Xu, F. Wang, J. Gao, L. Zhou, G. Yang, Catal. Lett. 108 (2006) 137-140.

[16] Y. Su, L.-C. Wang, Y.-M. Liu, Y. Cao, H.-Y. He, K.-N. Fan, Catal. Commun. 8 (2007) 21812185.

[17] K. Yamaguchi, H. Kobayashi, T. Oishi, N. Mizuno, Angew. Chem. 124 (2012) 559-562.

[18] S.C. Kim, W.G. Shim, Appl. Catal. B: Environ. 98 (2010) 180-185.

[19] E.K. Nyutu, C.-H. Chen, S. Sithambaram, V.M.B. Crisostomo, S.L. Suib, J. Phys. Chem. C 112 
(2008) 6786-6793.

[20] Y. Uozumi, Y. Yamada, The Chemical Record 9 (2009) 51-65.

[21] C.P. Vinod, K. Wilson, A.F. Lee, J. Chem. Technol. Biotechnol. 86 (2011) 161-171.

[22] M.J. Schultz, M.S. Sigman, Tetrahedron 62 (2006) 8227-8241.

[23] T. Mallat, A. Baiker, Chem. Rev. 104 (2004) 3037-3058.

[24] S. Shylesh, V. Schünemann, W.R. Thiel, Angew. Chem. Int. Ed. 49 (2010) 3428-3459.

[25] Y. Ishii, S. Sakaguchi, T. Iwahama, Adv. Synth. Catal. 343 (2001) 393-427.

[26] A.E. Shilov, G.B. Shul'pin, Chem. Rev. 97 (1997) 2879-2932.

[27] Y. Yoshino, Y. Hayashi, T. Iwahama, S. Sakaguchi, Y. Ishii, J. Org. Chem. 62 (1997) 6810-6813.

[28] A.R. Dick, K.L. Hull, M.S. Sanford, J. Am. Chem. Soc. 126 (2004) 2300-2301.

[29] A.V. Shijina, N.K. Renuka, React. Kinet. Catal. Lett. 94 (2008) 261-270.

[30] J.-E. Bäckvall, Modern oxidation methods, John Wiley \& Sons, 2011.

[31] M.D. Nikalje, A. Sudalai, Tetrahedron 55 (1999) 5903-5908.

[32] T. Das, K. Chaudhari, E. Nandanan, A. Chandwadkar, A. Sudalai, T. Ravindranathan, S. Sivasanker, Tetrahedron Lett. 38 (1997) 3631-3634.

[33] Y. Bonvin, E. Callens, I. Larrosa, D.A. Henderson, J. Oldham, A.J. Burton, A.G. Barrett, Org. Lett. 7 (2005) 4549-4552.

[34] T.M.A. Shaikh, A. Sudalai, Eur. J. Org. Chem. 2008 (2008) 4877-4880.

[35] A.S. Poyraz, C.-H. Kuo, S. Biswas, C.K. King'ondu, S.L. Suib, Nat. Commun. 4 (2013).

[36] A.S. Poyraz, C.-H. Kuo, E. Kim, Y. Meng, M.S.I. Seraji, S.L. Suib, Chem. Mater. (2014).

[37] E. Stobbe, B. De Boer, J. Geus, Catal. Today 47 (1999) 161-167.

[38] H.C. Genuino, S. Dharmarathna, E.C. Njagi, M.C. Mei, S.L. Suib, J. Phys. Chem. C 116 (2012) 12066-12078.

[39] M. Özacar, A.S. Poyraz, H.C. Genuino, C.-H. Kuo, Y. Meng, S.L. Suib, Applied Catalysis A: Gen. 462 (2013) 64-74.

[40] Y.C. Son, V.D. Makwana, A.R. Howell, S.L. Suib, Angew. Chem. 113 (2001) 4410-4413. 
[41] A.S. Poyraz, O.m. Dag, J. Phys. Chem. C 113 (2009) 18596-18607.

[42] M. Arai, S. Nishiyama, S. Tsuruya, M. Masai, J. Chem. Soc., Faraday Trans. 92 (1996) 26312636.

[43] M. Genta, S. Nishiyama, S. Tsuruya, M. Masai, J. Chem. Soc., Faraday Trans. 92 (1996) 12671275.

[44] Q. Tang, X. Huang, C. Wu, P. Zhao, Y. Chen, Y. Yang, J. Mol. Catal. A: Chem. 306 (2009) 4853.

[45] Y. Li, D. Nakashima, Y. Ichihashi, S. Nishiyama, S. Tsuruya, Ind. Eng. Chem. Res. 43 (2004) 6021-6026.

[46] Z. Helwani, M. Othman, N. Aziz, J. Kim, W. Fernando, Applied Catalysis A: Gen. 363 (2009) 1-10.

[47] G. Martra, R. Ocule, L. Marchese, G. Centi, S. Coluccia, Catal. Today 73 (2002) 83-93.

[48] N. Zheng, G.D. Stucky, Chem. Commun. (2007) 3862-3864.

[49] S.K. Jana, P. Wu, T. Tatsumi, J. Catal. 240 (2006) 268-274.

[50] A. Abad, P. Concepción, A. Corma, H. García, Angew. Chem. Int. Ed. 44 (2005) 4066-4069.

[51] K. Yamamoto, T. Imaoka, W.-J. Chun, O. Enoki, H. Katoh, M. Takenaga, A. Sonoi, Nat. Chem. 1 (2009) 397-402.

[52] S. Dharmarathna, C.K. King'ondu, W. Pedrick, L. Pahalagedara, S.L. Suib, Chem. Mater. 24 (2012) 705-712.

[53] H. Cao, S.L. Suib, J. Am. Chem. Soc. 116 (1994) 5334-5342.

[54] J. Chen, J.C. Lin, V. Purohit, M.B. Cutlip, S.L. Suib, Catal. Today 33 (1997) 205-214.

[55] M. Climent, A. Velty, A. Corma, Green Chem. 4 (2002) 565-569.

[56] V.D. Makwana, Y.-C. Son, A.R. Howell, S.L. Suib, J. Catal. 210 (2002) 46-52.

[57] C. Doornkamp, V. Ponec, J. Mol. Catal. A: Chem. 162 (2000) 19-32.

[58] A.S. Poyraz, W. Song, D. Kriz, C.-H. Kuo, M.S.I. Seraji, S.L. Suib, ACS applied materials \& interfaces (2014). 
[59] S. Dharmarathna, C.K. King'ondu, L. Pahalagedara, C.-H. Kuo, Y. Zhang, S.L. Suib, Appl. Catal. B: Environ 147 (2014) 124-131.

[60] T. Takashima, K. Hashimoto, R. Nakamura, J. Am. Chem. Soc. 134 (2012) 1519-1527.

[61] B. Karimi, A. Biglari, J.H. Clark, V. Budarin, Angew. Chem. Int. Ed. 46 (2007) 7210-7213.

[62] M. Sankar, E. Nowicka, R. Tiruvalam, Q. He, S.H. Taylor, C.J. Kiely, D. Bethell, D.W. Knight, G.J. Hutchings, Chem. Eur. J. 17 (2011) 6524-6532.

[63] S. Meenakshisundaram, E. Nowicka, P.J. Miedziak, G.L. Brett, R.L. Jenkins, N. Dimitratos, S.H. Taylor, D.W. Knight, D. Bethell, G.J. Hutchings, Faraday Discuss. 145 (2010) 341-356.

[64] G. Majji, S. Guin, A. Gogoi, S.K. Rout, B.K. Patel, Chem. Commun. 49 (2013) 3031-3033.

[65] J. Zhang, G. Leitus, Y. Ben-David, D. Milstein, J. Am. Chem. Soc. 127 (2005) 10840-10841.

[66] C. Liu, S. Tang, L. Zheng, D. Liu, H. Zhang, A. Lei, Angew. Chem. 124 (2012) 5760-5764.

[67] S.K. Rout, S. Guin, K.K. Ghara, A. Banerjee, B.K. Patel, Org. Lett. 14 (2012) 3982-3985. 


\section{Graphical Abstract}

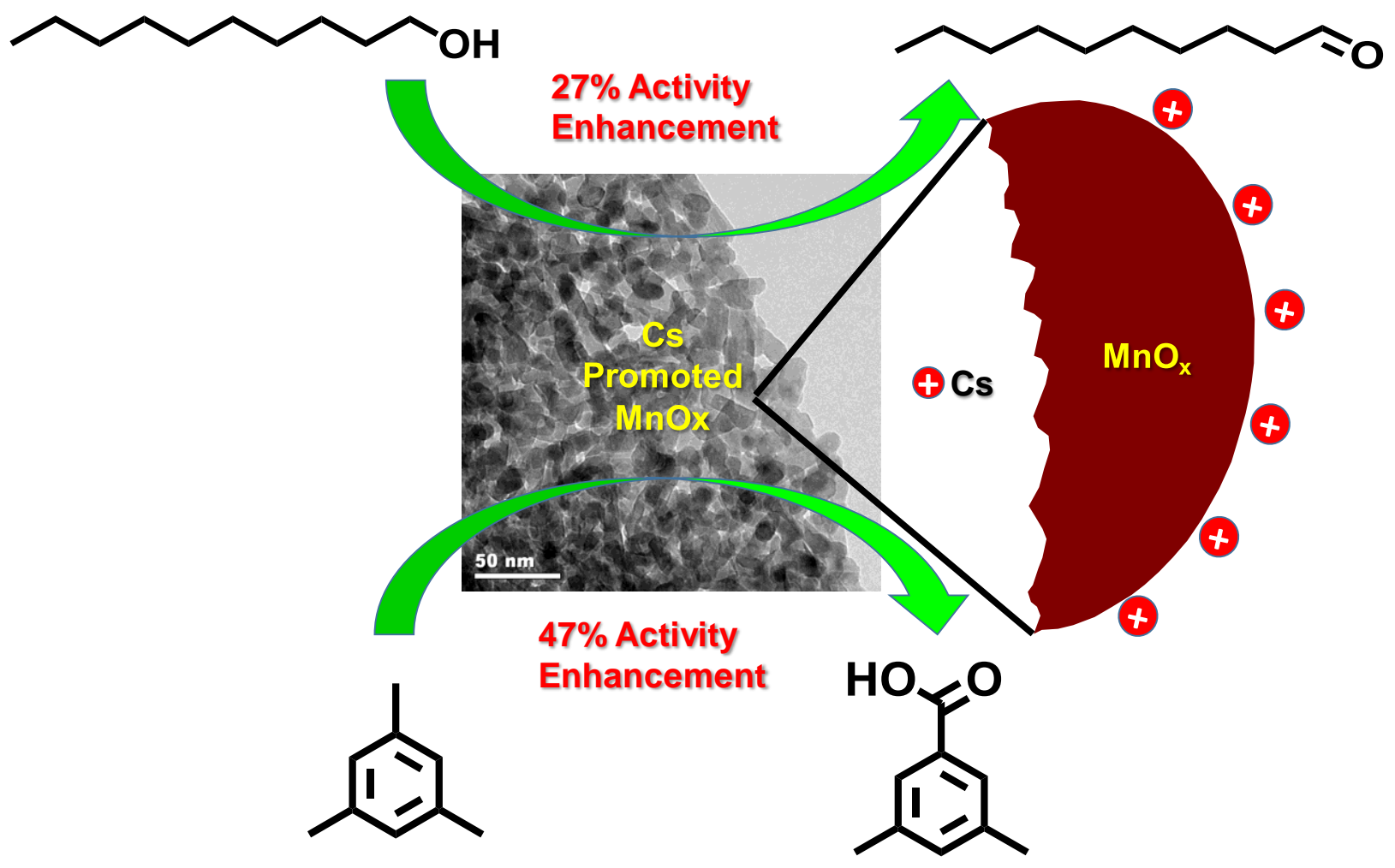

